\title{
Development of a competitive lateral flow immunoassay for progesterone: influence of coating conjugates and buffer components
}

\author{
Geertruida A. Posthuma-Trumpie • Jakob Korf • \\ Aart van Amerongen
}

Received: 2 June 2008 /Revised: 15 August 2008 / Accepted: 19 August 2008 / Published online: 14 September 2008

(C) The Author(s) 2008. This article is published with open access at Springerlink.com

\begin{abstract}
Several aspects of the development of competitive lateral flow immunoassays (LFIAs) are described. The quantitation of progesterone is taken as an example. The LFIA format consisted of a nitrocellulose membrane spotted with various progesterone conjugates as the test line. A mixture of primary antibody and secondary antibody adsorbed to colloidal carbon was used for signal generation. A digital scanner and dedicated software were used to quantitate the response. A reappraisal of the checkerboard titration, often used in the optimisation of immunoassays, is discussed. Surprisingly, the highest sensitivity of the LFIA format $\left(\mathrm{IC}_{50}\right.$ of $0.6 \mu \mathrm{g} \mathrm{L}{ }^{-1}$ progesterone in buffer) was achieved by using a high coating concentration of the analyte-protein conjugate and a high dilution of the antibody solution. Immediate addition of all reagents in LFIA was superior to premixing the components and allowing prereaction. Of several blocking agents tested bovine serum albumin was superior in performance, whereas the combination of ovalbumin and progesterone substantially influenced test results.
\end{abstract}

Keywords Immunochromatography.

Lateral flow immunoassay · Progesterone - Optimisation .

Blocking agents

G. A. Posthuma-Trumpie $\cdot$ J. Korf

Department of Psychiatry, University of Groningen, University Medical Centre Groningen (UMCG), Hanzeplein 1, P.O. Box 30.001, 9700 RB Groningen, The Netherlands

A. van Amerongen $(\square)$

Agrotechnology and Food Sciences Group,

Wageningen University and Research Centre,

Bornsesteeg 59, P.O. Box 17, 6700 AA Wageningen,

The Netherlands

e-mail: aart.vanamerongen@wur.nl

\section{Introduction}

Lateral flow immunoassays (LFIAs) are currently a versatile and therefore popular assay format, especially for applications outside the laboratory, i.e. "point of care/need" applications. LFIA is a one-step assay that is easy to perform, fast and cheap. Major advantages of LFIA are that no trained personnel or expensive apparatus is necessary. Furthermore, prepared strips can be stored for a long time without refrigeration, giving this method a fair chance in offlaboratory or resource-poor settings. A literature survey of the technique and a discussion of the strengths, weaknesses, opportunities and threats (a SWOT analysis) can be found elsewhere [1]. Primary anti-analyte antibody and labelled secondary anti-species antibody are used for recognition and signal generation. A test line of analyte-protein conjugate and a control line of anti-animal species antibody of the labelled antibody are sprayed onto plastic-backed membranes. A sample application pad and a conjugate release pad are applied to one end of the strip and an absorbent pad is applied at the distal end of the strip (cf. Fig. 1a). The absorbent pad wicks the fluid sample through the membrane. At the conjugate release pad, dried primary antibody and labelled secondary antibody are applied. Introduction of the sample onto the sample pad initiates the test.

Despite generally wide use [1], LFIAs for progesterone in the milk of diary animals have not been commercialized yet. The aim of the present investigation is to optimise the conditions to quantitate progesterone using a dry reagent immunoassay format.

When the analyte is a hapten, the design is restricted to the competitive format. In this format free antigen and immobilized antigen compete for a limited amount of antibody binding sites. When developing such an assay 
format a first screening is commonly used to find the optimal concentrations of antibody and antigen by a checkerboard titration [2]. However, another approach has been proposed using the total internal reflectance fluorescence (TIRF) technology [3-6], but that has not been explored practically when developing enzyme-linked immunosorbent assays (EIAs) or LFIAs. According to the latter studies a sensitive assay requires that the amount of antigen bound on the surface is high, which also enables a high dilution of the antibody. Using this strategy, the response at the chip is mass-transport-limited and not dependent on the kinetics of binding of antibody to antigen.

We report here on a reappraisal of the checkerboard titration in the development of competitive EIA and LFIA test formats. To this end, we used combinations of several monoclonal antibodies, raised against different analyteprotein conjugates. A combination with several coating conjugates was applied. In addition, we present some other aspects of the development of competitive LFIAs, such as the sequence of addition of sample and reagents and the influence of the blocking agent. Progesterone (P4) was chosen as the model hapten (cf. Fig. 1b).

\section{Experimental}

\section{Reagents}

Progesterone (pregn-4-ene-3,20-dione, P4), bovine serum albumin (BSA), chicken egg-white serum albumin (OVA) and thimerosal (2-(ethylmercuriomercapto)benzoic acid sodium salt) were purchased from Sigma-Aldrich Chemie BV (Zwijndrecht, the Netherlands). Lactoferrin was from DMV International (Veghel, the Netherlands), $\beta$-lactoglobulin was from Davisco (Geneva, Switzerland), and polyvinlylpyrroli- done (30 kDa), poly(methyl-vinylether-10-maleic anhydride) and teleostean gelatin were from Biodot Inc. (Irvine, CA, USA). All related steroids and steroid-BSA conjugates were purchased from Steraloids, Inc. (Newport, RI, USA), cf. Table 1. $\mathrm{NH}_{2}$-functionalized biotin with different length poly(ethylene oxide) linkers and neutravidin were from Pierce (Perbio Science Nederland BV, Etten-Leur, the Netherlands). Goat-anti-mouse IgG-fc-specific in the LFIA as secondary antibody was from Jackson Immunoresearch Europe (Sanbio, Uden, the Netherlands), and goatanti-mouse $\mathrm{IgG}$ conjugated to horseradish peroxidase (HRP) as secondary antibody in the EIA was purchased from DAKO Diagnostics (Heverlee, Belgium). Other chemicals were of the highest purity available and purchased from Merck (Amsterdam, the Netherlands). Water was of Milli Q quality (Millipore, Amsterdam, the Netherlands).

Materials and instruments

\section{Enzyme-linked immunosorbent assay}

Costar 3590 high-binding 96-well microplates were purchased from Corning BV Life Sciences (Schiphol-Rijk, the Netherlands). For the tests using antibodies raised with P4 conjugates without BSA all solutions contained BSA for blocking, otherwise OVA was used.

The tests were performed essentially as described in ref. [7] with slight modifications as described in ref. [8]. In anticipation of the final assay format being the LFIA, antibody incubation times were reduced to $10 \mathrm{~min}$. Briefly, P4 conjugated to BSA or OVA was coated overnight at $4{ }^{\circ} \mathrm{C}$ or $1 \mathrm{~h}$ at $37^{\circ} \mathrm{C}$ in high-binding microplate wells. When using the $\mathrm{P} 4-\mathrm{HS}-\mathrm{PE}_{2}$-biotin or $\mathrm{P} 4-\mathrm{HS}-\mathrm{PE}_{3}$-biotin conjugates, a mixture of neutravidin and conjugated $\mathrm{P} 4$ was coated in the wells. The neutravidin/biotin molar ratio was 1:3.4. After blocking, a mixture of $50 \mu \mathrm{L}$ of serial dilutions
Fig. 1 Schematic of a lateral flow immunoassay test format and a model of the progesterone molecule: a schematic setup of an inhibition LFIA (not to scale), showing the response when no analyte is present (upper panel) or when analyte is present (lower panel); b model of the progesterone molecule, a representation in pdb format and the numbering of $\mathrm{C}$ atoms in the steroid part of the molecule, where the keto group at position 3 and two methyl side chains at positions 10 and 13 were removed for clarity a

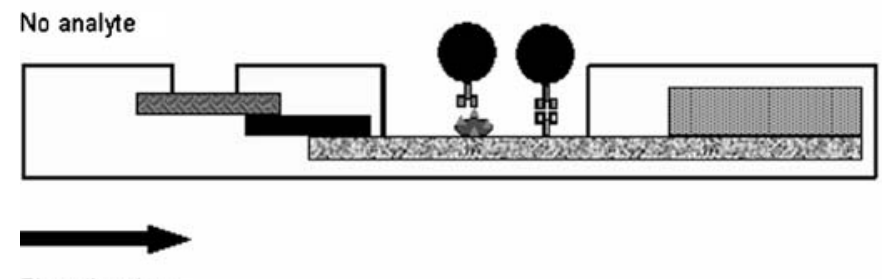

Flow direction

Analyte

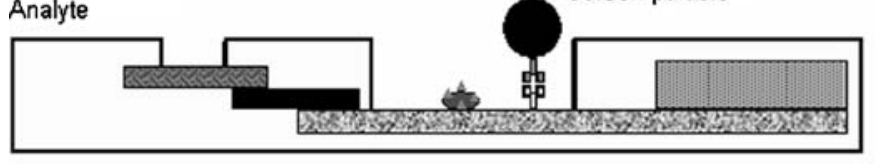

Sample pad Nitrocellulose membrane

Absorbent pad

Conjugate pad

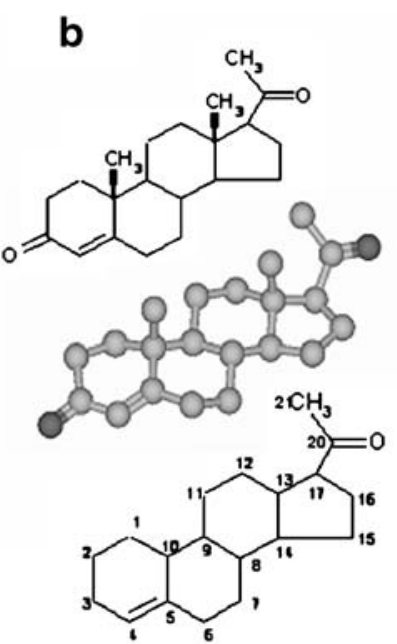


Table 1 Overview of $\mathrm{COOH}$-functionalised progesterone haptens and $\mathrm{NH}_{2}$-biotin-poly(ethylene oxide) reagents<smiles>CC(=O)C1CCC2C3CCC4=C/C(=N/OCC(=O)O)CCC4(C)C3CCC12C</smiles>

Progesterone 3-CMO<smiles>CC(=O)C1CCC2C3CCC4=CC(=O)CCC4(C)C3C(OC(=O)CCC(=O)O)CC12C</smiles>

Progesterone $11 \alpha-H S$<smiles>CC(=O)C1CCC2C3CC(OC(=O)CCC(=O)O)C4=CC(=O)CCC4(C)C3CCC12C</smiles>

Progesterone 6 $\beta$-HS<smiles>CC(=O)C1(O)CCC2C3CCC4=C/C(=N/OCC(=O)O)CCC4(C)C3CCC21C</smiles>

Progesterone-17-ol-3-CMO<smiles>CC12CCC(=O)C=C1CCC1C2CCC2(C)C(C(=O)COC(=O)CCC(=O)O)CCC12</smiles>

Progesterone $21 \alpha$-HS<smiles>CC(=O)C1CCC2C3C(CCC12C)C1(C)CCC(=O)C=C1C[C@H]3SCCC(=O)O</smiles>

Progesterone-7 $\alpha$-CET<smiles>NCCOCCOCCNC(=O)CCCCC1SCC2NC(=O)NC21</smiles>

Biotin $\mathrm{PE}_{2}$<smiles>NCCOCCOCCOCCNC(=O)CCCCC1SCC2NC(=O)NC21</smiles>

Biotin- $\mathrm{PE}_{3}$

Abbreviations: $C E T$ carboxyethylthioether, $C M O$ carboxymethyloxime, $H S$ hemisuccinate, $P E_{2}$ two poly(ethylene oxide) moieties, $P E_{3}$ three poly (ethylene oxide) moieties

of a P4 standard followed by $50 \mu \mathrm{L}$ of an appropriate antibody dilution in assay buffer were allowed to compete with immobilized P4 conjugate. After incubating and washing, secondary antibody coupled to HRP was added and reacted for $10 \mathrm{~min}$. After washing to remove excess label, substrate solution was added to the wells, and the enzyme reaction was stopped after a predetermined time by addition of $2 \mathrm{~mol} \mathrm{~L}^{-1} \mathrm{H}_{2} \mathrm{SO}_{4}$. Absorbance values $\left(A_{450}\right)$ were measured with a Wallac Victor 1420 Multilabel Counter (PerkinElmer, Wellesly, MA, USA). 


\section{Lateral flow immunoassay}

Costar 3595 low-binding 96-well microplates were purchased from Corning BV Life Sciences (Schiphol-Rijk, the Netherlands). For the initial tests using antibodies raised with P4 conjugates without BSA all solutions contained BSA for blocking, otherwise OVA was used, except for the tests on blocking agents. Tests were performed essentially as described in ref. [9]. Briefly, the P4-protein conjugate solution in spraying buffer ( $1 \mu \mathrm{L} /$ strip) was spotted using a TLC spotter (Camag Linomat IV, Camag, Berlin, Germany) at an amount ranging from 7 to $1,000 \mathrm{ng} / \mathrm{strip}$ on plastic-backed nitrocellulose membranes with a pore size of $12 \mu \mathrm{m}, \mathrm{AE} 100$ (Whatman/Schleicher and Schuell, 's-Hertogenbosch, the Netherlands). When using the P4$\mathrm{HS}-\mathrm{PE}_{2}$-biotin or $\mathrm{P} 4-\mathrm{HS}-\mathrm{PE}_{3}$-biotin conjugates, a mixture of neutravidin and conjugated $\mathrm{P} 4$ was sprayed on the strips at the test line. The neutravidin/biotin molar ratio was 1:3.4. The membranes were dried overnight at $37^{\circ} \mathrm{C}$. A second plastic backing was applied and the membranes were cut into $0.5 \times 5 \mathrm{~cm}$ strips using a Biodot CM4000 cutter (Biodot Inc., Irvine, CA, USA). An absorption pad of cellulose was applied (Whatman/Schleicher and Schuell, 's-Hertogenbosch, the Netherlands) to the prepared membranes which were then stored desiccated in the dark at room temperature.

In low-binding microplate wells $50 \mu \mathrm{L}$ of sample was mixed with $50 \mu \mathrm{L}$ of an appropriate dilution of primary antibody and $10 \mu \mathrm{L}$ of a 1:10 dilution of carbon-labelled secondary antibody (0.2 $\mathrm{g} \mathrm{L}^{-1}$ carbon nanoparticles) in running buffer. A test strip was positioned vertically in the well containing this mixture and the test solution was allowed to run. After complete drying the pixel grey volume of the test line was recorded using an Epson 3200 Photo scanner (Seiko Epson, Nagano, Japan) and dedicated software. Scans were performed at 1,200-dpi resolution using 16-bit grey scale. The resulting images were saved as 16-bit TIFF files and processed by image analysis software (TotalLab, Nonlinear Dynamics, Newcastle upon Tyne, UK). Essentially, the software records the grey level of every pixel in the picture frame as indicated by the user on a scale of 0-255 and integrates the data of all pixels. Blank pixel grey volume on every individual strip was measured just below the test line and subtracted from the pixel grey volume of the test line. Images used for Fig. 4b were cropped and modified by applying the "sharpen" function in Photoshop 5 (Adobe Systems Inc., San Jose, CA, USA). No other modifications were applied.

For experiments on maximal performance and reproducibility of the LFIA tests, several protocols for the addition sequence of reagents were used according to Scheme 1. These tests were performed twice in triplicate.

\section{Solutions}

The coating buffer comprised $0.95 \mathrm{~g} \mathrm{Na}_{2} \mathrm{CO}_{3}$ and $44 \mathrm{~g}$ $\mathrm{NaHCO}_{3}$ in $1 \mathrm{~L} \mathrm{H}_{2} \mathrm{O}$, pH 9.6. Phosphate-buffered saline (PBS) comprised $1.265 \mathrm{~g} \mathrm{NaH}_{2} \mathrm{PO}_{4} \cdot \mathrm{H}_{2} \mathrm{O}, 12.10 \mathrm{~g} \mathrm{Na}_{2} \mathrm{HPO}_{4} \cdot 12 \mathrm{H}_{2} \mathrm{O}$, $8.5 \mathrm{~g} \mathrm{NaCl}$ and $0.2 \mathrm{~g}$ thimerosal in $1 \mathrm{~L} \mathrm{H}_{2} \mathrm{O}, \mathrm{pH}$ 7.2. Assay buffer comprised PBS with $1.0 \mathrm{~g}$ blocking agent in $1 \mathrm{~L}$, $\mathrm{pH}$ 7.2. Spraying buffer comprised $5 \mathrm{mmol} \mathrm{L}^{-1}$ boric acid/ sodium tetraborate, $\mathrm{pH} 8.5$; running buffer comprised $0.1 \mathrm{~mol} \mathrm{~L}{ }^{-1}$ boric acid/sodium tetraborate, $10 \mathrm{~g} \mathrm{~L}^{-1}$ blocking agent, $0.5 \mathrm{~mL} \mathrm{~L}^{-1}$ Tween 20 and $0.2 \mathrm{~g} \mathrm{~L}^{-1} \mathrm{NaN}_{3}$, $\mathrm{pH}$ 8.5.

\section{Monoclonal antibodies}

A monoclonal antibody against P4-11 $\alpha$-hemisuccinatebovine thyroglobulin (11-BTG) was developed in mice under supervision of the Animal Sciences Group of Wageningen UR (ASG-WUR, Lelystad, the Netherlands) in accordance with the Institute's ethical guidelines in collaboration with MCA Development (Groningen, the Netherlands). Hybridomas were produced as described by Fazekas de St. Groth and Scheidegger [10] and the hybridoma cell line that secreted an antibody against P4 was selected resulting in the mAb 49.3. This mAb exhibited high affinity to P4 (D.F.M. van de Wiel, ASG-WUR; personal communication). Supernatant was purified by affinity chromatography on ProteinA-Sepharose. Aliquots of the $\mathrm{mAb}$ in a solution of $0.9 \mathrm{~g} \mathrm{~L}^{-1}$ in $500 \mathrm{~g} \mathrm{~L}^{-1}$ glycerol/ PBS were stored at $-20{ }^{\circ} \mathrm{C}$. The antibody was thoroughly characterized in relation to cross-reactivity to related steroids in the EIA format where the progesterone-7 $\alpha$ CET-BSA conjugate was coated in the microplate wells. The level of cross-reactivity was determined by comparing the $50 \%$ inhibition concentration of progesterone with $50 \%$ inhibition concentration of the competing compound. To this end a standard curve of progesterone with serial dilutions $(1: 1)$ in the range of $1-100 \mu \mathrm{g} \mathrm{L^{-1 }}$ and serial dilutions $(1: 10)$ of the competing compound in the range of
Scheme 1 Protocols for reagent addition in LFIA format

\begin{tabular}{cl}
\hline Protocol \# & Sequence of addition of sample and reagents \\
\hline 1 & All reagents were added immediately to sample. \\
2 & Pre-incubation of sample and primary antibody for 30 min. \\
3 & Pre-mixing of primary and secondary antibody, immediate addition to sample. \\
4 & Pre-incubation of primary and secondary antibody for 30 min. \\
\hline
\end{tabular}


$1-10,000 \mu \mathrm{g} \mathrm{L}^{-1}$ were used. Goat-anti-mouse coupled to HRP was used as the secondary antibody.

Several commercially available monoclonal purified mouse antibodies raised against P4-11 $\alpha$-HS-BSA (11-BSA) were purchased: M630408 (Fitzgerald Industries International, Concord, MA, USA), P2PXM207 (Acris Antibodies Hiddenhausen, Germany) and 4P01 (LabVision/Neomarkers, Immunologic, Duiven, the Netherlands). Cross-reactivity of monoclonal antibody $4 \mathrm{P} 01$ with related steroid compounds was reported in ref. [11] in microplate format.

\section{Antigen conjugates}

A conjugate of P4-11 $\alpha$-HS (Steraloids, Newport, RI, USA) with OVA was prepared by using the Imject Immunogen EDC Kit with OVA (Pierce, Perbio Science Nederland, Etten-Leur, the Netherlands). The protein conjugate was dialyzed against Milli $\mathrm{Q}$ water using a membrane with cutoff value of $15 \mathrm{kDa}$ and lyophilised (P4-11 $\alpha$-HS-OVA). A conjugate of P4-11 $\alpha$-HS and OVA was also obtained from the Weizmann Institute, Rehovot, Israel (P4-11 $\alpha$-HS-OVA). Conjugates of $\mathrm{P} 4-\mathrm{HS}$ to $\mathrm{PE}_{2}$-biotin or $\mathrm{PE}_{3}$-biotin (Pierce, Perbio Science Nederland, Etten-Leur, the Netherlands) were prepared by the mixed anhydride method [12] with

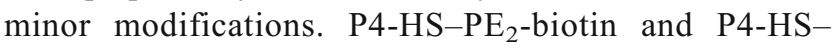
$\mathrm{PE}_{3}$-biotin conjugates were purified using a preparative HPLC system with mass detection (Waters Corp., Milford, MA, USA) and fractions with the required mass were lyophilised. All conjugates were stored desiccated at $-20{ }^{\circ} \mathrm{C}$ in the dark.

\section{Statistics}

Calculations of best-fit formulae, $\mathrm{IC}_{50}$ values (i.e. the concentration at $50 \%$ of the blank signal) and design of graphs for Figs. 2, 4a and 5 were done using the program Microcal Origin version 6.0 (Microcal Software Inc., Northampton, MA, USA). The percentage of cross-reactivity is defined as the $\mathrm{IC}_{50}$ of progesterone divided by the $\mathrm{IC}_{50}$ of the related steroid times 100\%. The program Microsoft Excel 2000 (Microsoft Nederland BV, Amsterdam-Z.O., the Netherlands) was used to calculate the SD and SEM data, and to prepare Fig. 3.

\section{Results and discussion}

Characterization of the monoclonal antibody mAb 49.3

The monoclonal antibody mAb 49.3 was thoroughly characterized with respect to cross-reactivity using the EIA format. A high degree of cross-reactivity was found with $11 \alpha$-hydroxyprogesterone (not shown). This is not unexpected because the antibody was produced by hybridomas

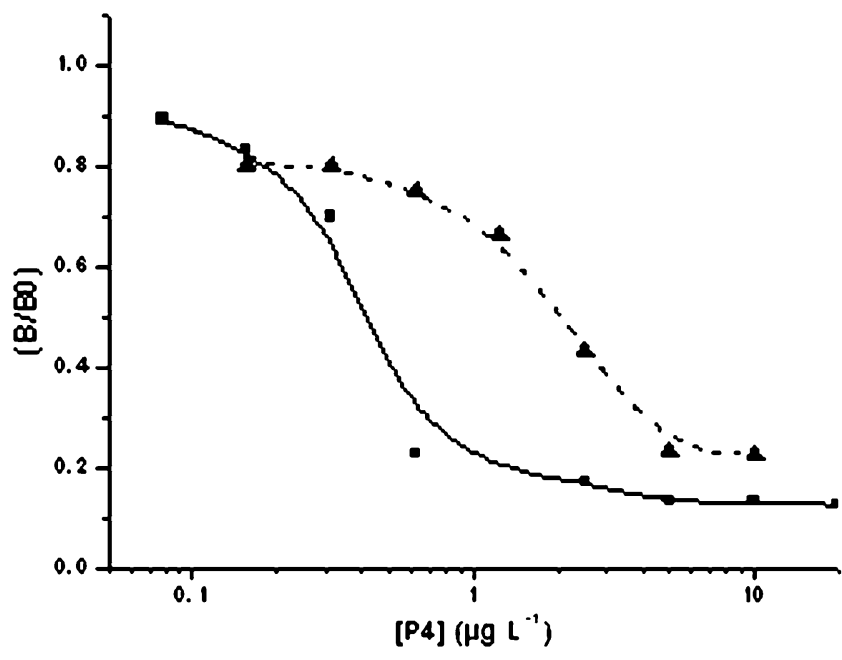

Fig. 2 Typical example of the sensitivity of the assay in the microplate EIA, given as the $B / B_{0}$ at $450 \mathrm{~nm}$. Recognition was performed with $\mathrm{mAb}$ 49.3. Dashed line coating concentration of $33 \mu \mathrm{g} \mathrm{L}^{-1} \mathrm{P} 4-7 \alpha$-CET-BSA, solid line coating concentration of $10 \mathrm{mg} \mathrm{L}^{-1}$ with the same conjugate. The antibody dilution was chosen in such a way that the blank signal was always at an $A_{450}$ of 1.5 . SDs were typically below $10 \%$

from mice immunized against progesterone-11 $\alpha$-HS-BTG. An acceptable level of cross-reactivity was found for the other steroid compounds tested (Table 2).

\section{Enzyme-linked immunosorbent assay}

Preliminary tests were used in a checkerboard titration to determine optimal concentrations of the antibody and the P4 conjugate under consideration. Several combinations performed well, whereas, to our surprise, the mAb M630408 using OVA as blocking agent did not give a satisfactory response with any of the antigen conjugates (not shown). At that time this observation was not understood, but later on the effect of the OVA used as blocking component became clear (cf. Influence of blocking agents on the response). This might have been the reason for the unsatisfactory performance of this $\mathrm{mAb}$ with all antigen-conjugate combinations tested.

In a standard checkerboard titration experiment, the best performance was obtained using P4-7 $\alpha$-CET-BSA at a coating concentration of $33 \mu \mathrm{g} \mathrm{L}^{-1}$ and a $1: 1,800$ dilution of the antibody mAb 49.3 preparation. Application of the strategy as mentioned in ref. [5] is depicted in Fig. 2. The antibody dilution was chosen in such a way that the blank signal was always at an $A_{450}$ of 1.5 . As a typical example the response of $\mathrm{mAb} 49.3$ using P4-7 $\alpha$-CET-BSA is shown for assay buffer containing $1 \mathrm{~g} \mathrm{~L}^{-1}$ BSA spiked with serial dilutions of $\mathrm{P} 4$ and low or high coating concentrations and $\mathrm{mAb}$ dilutions. The $\mathrm{IC}_{50}$ of the standard curve when using a coating concentration of $33 \mu \mathrm{g} \mathrm{L}^{-1}$ was $2.4 \mu \mathrm{g} \mathrm{L}^{-1}$, whereas an $\mathrm{IC}_{50}$ of $0.4 \mu \mathrm{g} \mathrm{L}^{-1}$ was obtained for the curve resulting 


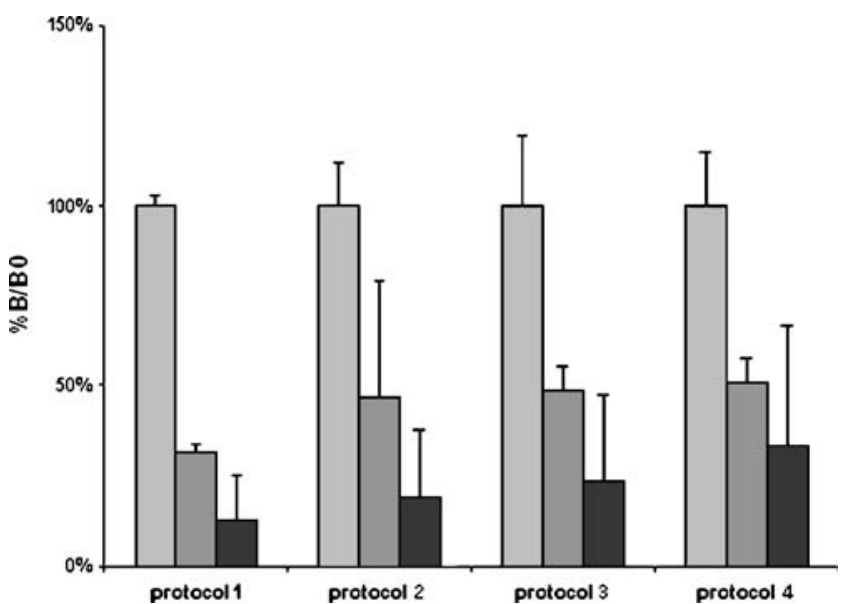

Fig. 3 Response of $0 \mu \mathrm{g} \mathrm{L}^{-1}$ (light grey), $10 \mu \mathrm{g} \mathrm{L}^{-1}$ (dark grey) or $50 \mu \mathrm{g} \mathrm{L}^{-1} \mathrm{P} 4$ (black) on different protocols of sequence of addition of reagents. Protocol 1 immediate addition of all reagents to the sample, protocol 2 preincubation of sample with primary antibody, protocol 3 premixing of primary and secondary antibodies, protocol 4 preincubation of primary and secondary antibodies

from the incubation at a coating concentration of $10 \mathrm{mg} \mathrm{L}^{-1}$. The better sensitivity of the assay with a high coating concentration is in-line with another study [5], which showed similar results for an immunosensor for the quantitation of P4 in buffer and bovine milk.

Surprisingly, although the mAb P2PXM207 showed a good performance in the checkerboard titration using OVA allowing a high antibody dilution, no inhibition was seen when serial dilutions of $\mathrm{P} 4$ in the required concentration range were applied.

\section{Lateral flow immunoassay}

\section{Influence of the sequence of addition of reagents and sample}

Tests were done to reveal the influence on the performance of the LFIA with respect to the sequence of addition of reagents and sample and, possibly, preincubation. Immediate mixing of all reagents (protocol 1), favourable for a simple and fast assay, was found to be superior to the other protocols (cf. Fig. 3), with an intra-assay SD of $1-20 \%$ and an interassay SEM of $20-30 \%$. For the other protocols an intra-assay SD of $10-60 \%$ and an interassay SEM of 20 $40 \%$ were calculated.

\section{Influence of coating concentration}

In a preliminary checkerboard titration the responses of antibody-antigen combinations were screened. The monoclonal antibody mAb 49.3 recognized all $\mathrm{P} 4$ conjugates, indicating a more general antigenic interaction (cf. Table 3). In addition, the Neomarkers mAb 4P01 was exclusively tested in this format. This $\mathrm{mAb}$ performed best when using the P4-3-CMO-BSA coating conjugate. However, there was no recognition when using the $\mathrm{P} 4-6 \beta-\mathrm{PE}_{2}$-biotin, $\mathrm{P} 4-6 \beta-$ $\mathrm{PE}_{3}$-biotin and P4-7 $\alpha$-CET-BSA conjugate (cf. Table 3). For this antibody, the antigenic determinant is anticipated at the C-3, C-11 and/or C-21 moieties (cf. Fig. 1b).

In a standard checkerboard titration experiment, the best performance was obtained using P4-7 $\alpha$-CET-BSA at a

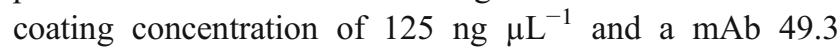
concentration of $2.5 \mathrm{ng} \mathrm{mL}^{-1}$. It was not clear from the checkerboard titration tests performed in this format that, due to the different kinetics, the relationship between a high coating concentration and consequently a high dilution of the antibody as stated in ref. [5] was valid here as well. Application of this strategy in an inhibition assay is depicted in a typical example using mAb 49.3 and P4-7 $\alpha$-CET-BSA in Fig. 4a. The mAb concentration was chosen in such a way that the response of a buffer solution without $\mathrm{P} 4$ was always at a pixel grey volume of $1 \times 10^{5}$, a value that can be clearly seen by the naked eye. The $\mathrm{IC}_{50}$ with a coating concentration of $125 \mathrm{ng} \mu \mathrm{L}^{-1}$ was, as obtained from the standard curve, $5.5 \mu \mathrm{g} \mathrm{L}^{-1}$, and with a coating concentration of $1,000 \mathrm{ng} \mu \mathrm{L}^{-1}$ the $\mathrm{IC}_{50}$ was $1.2 \mu \mathrm{g} \mathrm{L}^{-1}$. A similar response was observed when $\mathrm{mAb} 4 \mathrm{P} 01$ and $\mathrm{P} 4-3-\mathrm{CMO}$ BSA were used with BSA as blocking agent (results not shown). Using this latter combination an $\mathrm{IC}_{50}$ of $2.7 \mu \mathrm{g} \mathrm{L}$ with a coating concentration of $62.5 \mathrm{ng} \mu \mathrm{L}^{-1}$ was obtained, whereas at a coating concentration of $1,000 \mathrm{ng} \mu \mathrm{L}^{-1}$ an $\mathrm{IC}_{50}$ of $0.6 \mu \mathrm{g} \mathrm{L}^{-1}$ was obtained. No inhibition was seen with OVA as blocking agent. An example of an inhibition assay on the strips is depicted in Fig. 4 b.

In a typical inhibition experiment with the P4-PE conjugates it can be concluded that the binding of the antibody $\mathrm{mAb} 49.3$ and $\mathrm{mAb} 4 \mathrm{P} 01$ to the conjugate at the 11-position is strongest, as these antibodies were raised with a similar P4-protein conjugate. As a consequence, the competition with free P4 is less sensitive (cf. Table 4). These results are in accordance with earlier observations

Table 2 Cross-reactivity of the monoclonal antibody mAb 49.3 in the EIA format

Steroid Cross-reactivity $(\%)^{\mathrm{a}}$

Progesterone

100

Cortisol

0.04

Corticosterone

0.5

Estrone

0.03

Estradiol

$<0.03$

Pregnenolone

$<0.03$

$5 \alpha$-Pregnane-3,20-dione

0.3

${ }^{\mathrm{a}}$ Cross-reactivity is defined as the $\mathrm{IC}_{50}$ of progesterone divided by the $\mathrm{IC}_{50}$ of the related steroid times $100 \%$ 
Table 3 LFIA format, response in checkerboard titration to different P4-protein conjugates on several antibodies

\begin{tabular}{|c|c|c|c|}
\hline \multirow[t]{2}{*}{ Coating conjugate } & \multicolumn{3}{|l|}{ Immunogen (antibody; brand) } \\
\hline & 11-BTG (mAb 49.3; ASG-WUR) ${ }^{\mathrm{a}}$ & 11-BSA (mAb P2PXM207; Acris) ${ }^{\mathrm{b}}$ & 11-BSA (mAb 4P01; Neomarkers) ${ }^{\mathrm{a}}$ \\
\hline P4-3-CMO-BSA & ++ & ++ & ++ \\
\hline P4-3-CMO-17-ol-BSA & ++ & ++ & ++ \\
\hline P4-7 $\alpha$-CET-BSA & ++ & ++ & - \\
\hline P4-21-HS-BSA & ++ & NT & ++ \\
\hline P4-11 $\alpha$-HS-OVA & ++ & ++ & ++ \\
\hline P4-6 $\beta$-HS-biotin-PE 2 & ++ & NT & - \\
\hline P4-6 $\beta$-HS-biotin-PE 3 & ++ & NT & - \\
\hline P4-11 $\alpha$-HS-biotin-PE 2 & ++ & NT & ++ \\
\hline P4-11 $\alpha$-HS-biotin-PE & ++ & NT & ++ \\
\hline P4-21-HS-biotin-PE 2 & ++ & NT & ++ \\
\hline P4-21-HS-biotin-PE 3 & ++ & NT & ++ \\
\hline
\end{tabular}

++ good response, - no response, $N T$ not tested

${ }^{\mathrm{a}}$ Blocking with $10 \mathrm{~g} \mathrm{~L}^{-1}$ BSA in running buffer

${ }^{\mathrm{b}}$ Blocking with $10 \mathrm{~g} \mathrm{~L}^{-1}$ OVA in running buffer

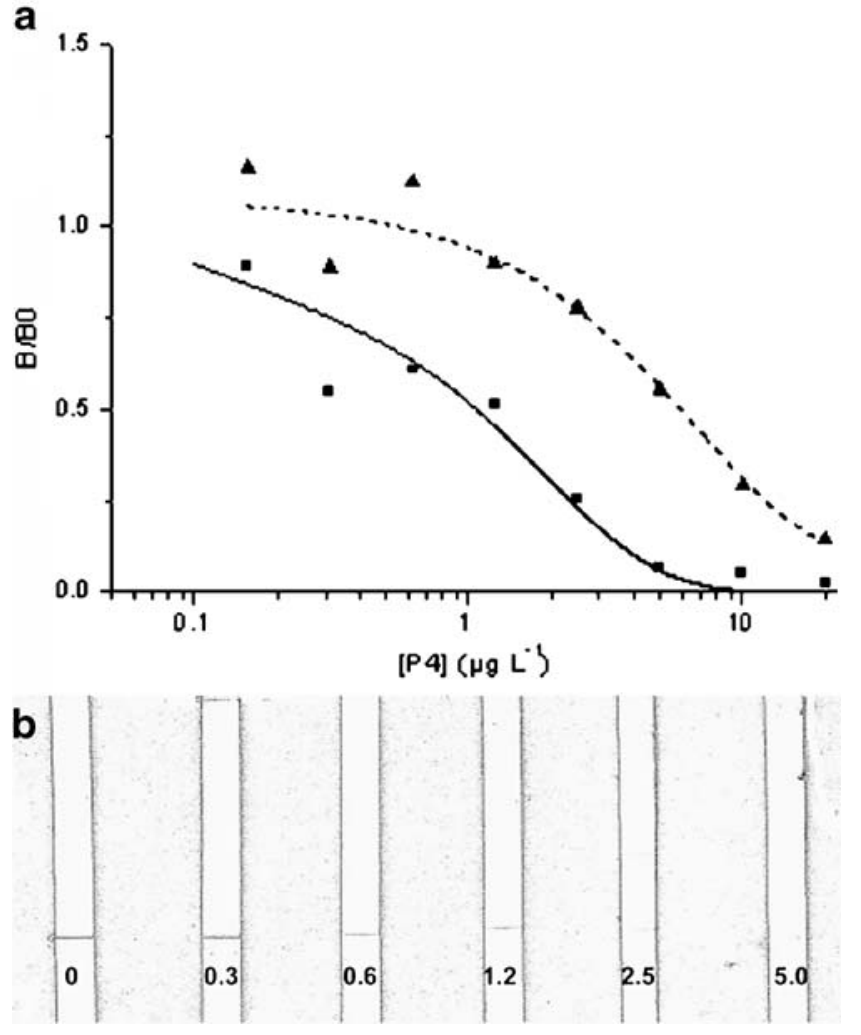

Fig. 4 a Typical example of the sensitivity of the assay in the LFIA format using mAb 49.3 and P4-7 $\alpha$-CET-BSA: dashed line coating concentration $125 \mathrm{ng} \mu \mathrm{L}^{-1}$, solid line coating concentration $1,000 \mathrm{ng} \mu \mathrm{L}^{-1}$. b Scan of LFIA strips in an inhibition assay on $\mathrm{P} 4$ using $\mathrm{mAb} 4 \mathrm{P} 01$ and $\mathrm{P} 4-3-\mathrm{CMO}-\mathrm{BSA}$ at a coating concentration of $1,000 \mathrm{ng} \mu \mathrm{L}^{-1}$. The antibody dilution was chosen in such a way that the blank signal was always at a pixel grey volume of $1 \times 10^{5}$. SDs were typically below $20 \%$
[13-15]. A slight tendency for a better sensitivity with the longer spacer can be observed. This is in agreement with the results reported in ref. [16]. However, due to the hygroscopic nature and consequently the difficulty in handling, these conjugates were not used in subsequent experiments.

\section{Influence of blocking agents on the response}

To our surprise, the monoclonal antibodies Acris P2PXM207 and Neomarkers mAb 4P01, both raised with P4-11 $\alpha$-HSBSA and both allowing a high dilution in the checkerboard titration, did not show any inhibition when using OVA as blocking protein. This phenomenon was seen in the EIA and LFIA formats. In a study using a TIRF format [6], OVA was also used as a blocking agent with mAb BM2068. However, this antibody is no longer available, and the authors advised P2PXM207 instead (Dr N.D. Käppel, Eberhard-Karls-University of Tuebingen, personal commu-

Table 4 Sensitivity of preliminary LFIA test for several P4-PE-biotin conjugates

\begin{tabular}{|c|c|c|}
\hline Coating conjugate & $\begin{array}{l}\mathrm{mAb} 49.3 \\
\mathrm{IC}_{50} \\
\left(\mu \mathrm{g} \mathrm{L}^{-1}\right)\end{array}$ & $\begin{array}{l}\mathrm{mAb} 4 \mathrm{P} 01 \\
\mathrm{IC}_{50}\left(\mu \mathrm{g} \mathrm{L}^{-1}\right)\end{array}$ \\
\hline P4-6 $\beta$-HS-PE ${ }_{2}$-biotin & 13 & No recognition \\
\hline $\mathrm{P} 4-6 \beta$-HS-PE $-\mathrm{P}_{3}$-biotin & 4 & No recognition \\
\hline P4-11 $\alpha$-HS-PE - -biotin & 28 & $>40$ \\
\hline P4-11 $\alpha$-HS-PE - -biotin & 24 & 21 \\
\hline P4-21-HS-PE 2 -biotin & 7 & 13 \\
\hline P4-21-HS-PE - -biotin & 7 & 10 \\
\hline
\end{tabular}

A mixture of neutravidin and P4-biotin conjugate (molar ratio neutravidin/biotin 1:3.4) was sprayed on the test line at a concentration of $500 \mathrm{ng} \mu \mathrm{L}^{-1}$ neutravidin 
Fig. 5 Dependency of the test response on the OVA concentration in running buffer: a absolute response of blank buffer on increasing OVA concentration and decreasing BSA concentration using P4-3-CMO-BSA and $\mathrm{mAb}$ $4 \mathrm{P} 01$, b difference in response between $P_{0}$ (no P4) and $P_{20}$ (20 $\mathrm{g} \mathrm{L} \mathrm{L}^{-1}$ P4) using P4-3-CMO-BSA and $\mathrm{mAb}$ 4P01, c absolute response of blank buffer on increasing OVA concentration and decreasing BSA concentration using P4-7 $\alpha$-CET-BSA and $\mathrm{mAb}$ 49.3, $\mathbf{d}$ difference in response between $P_{0}$ (no P4) and $P_{20}$ (20 $\mu \mathrm{g} \mathrm{L}^{-1}$ P4) using P4-7 $\alpha$-CET-BSA and $\mathrm{mAb}$ 49.3. SDs were typically below $20 \%$
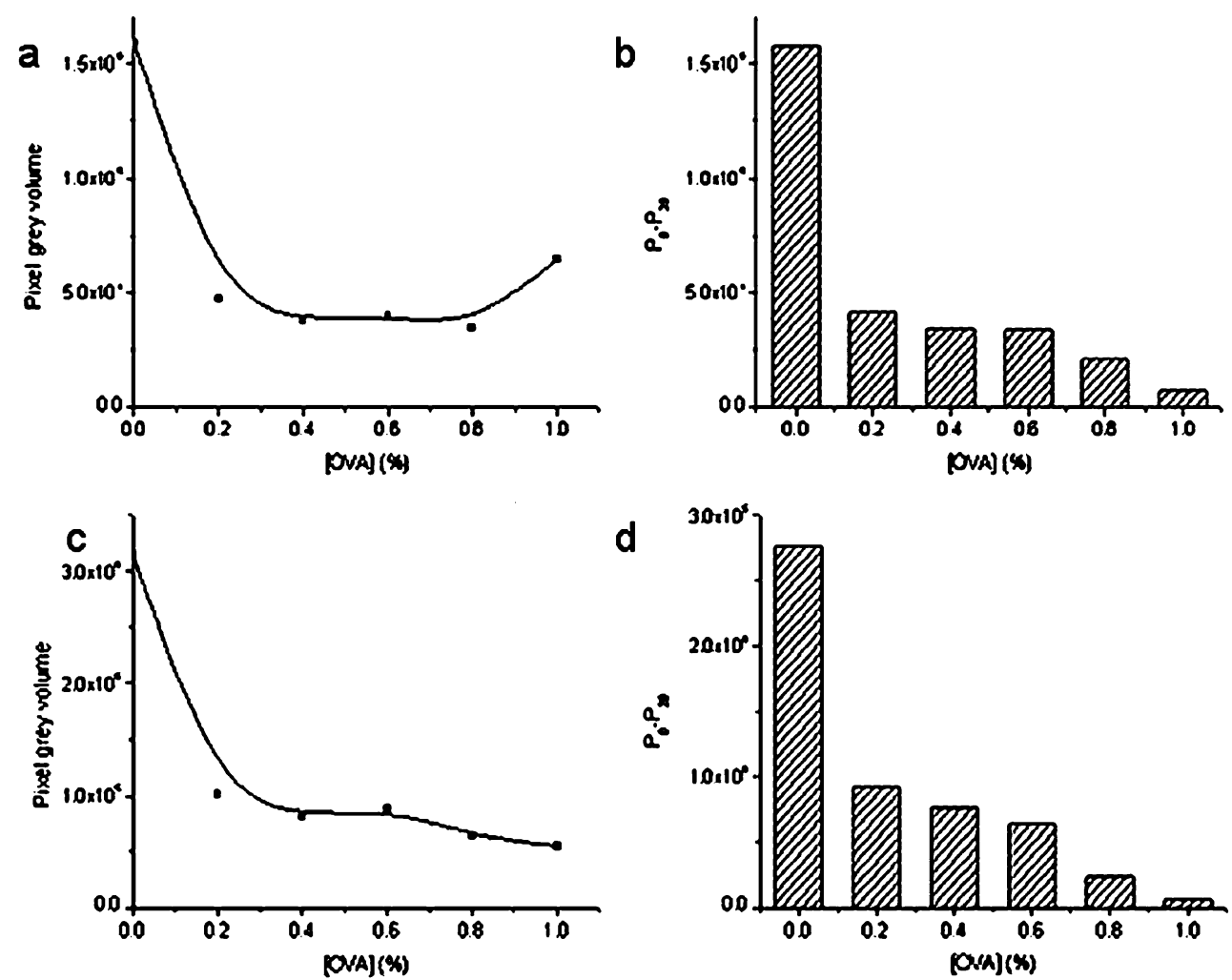

nication), but in this and a previous publication the OVA concentration was not mentioned $[5,6]$.

To elucidate this discrepancy, OVA was also used to perform an inhibition assay using mAb 49.3 that was not raised using a conjugate with BSA and could be used with BSA and/or OVA as blocking agent. When using this $\mathrm{mAb}$ no inhibition was observed when using OVA as blocking agent (result not shown). A preliminary test on the influence of BSA as blocking agent using the Neomarkers mAb 4P01 revealed that in this format there was no serious interference of BSA on the response (not shown). A series of BSA-OVA combinations in running buffer were prepared, and using monoclonal antibody $\mathrm{mAb} 49.3$ or $\mathrm{mAb} 4 \mathrm{P} 01$ the influence on the assay performance upon increasing concentrations of OVA was elucidated (cf. Fig. 5).

The results on OVA strongly suggest that OVA binds to the $\mathrm{P} 4$ conjugate at the test line, or shields the $\mathrm{P} 4$ conjugate from recognition by the antibody, since the blank signal, i.e. without addition of $20 \mu \mathrm{g} \mathrm{L}^{-1}$ free P4, is strongly reduced upon addition of OVA (cf. Fig. 5a and c). Moreover, the response difference between the $0 \mu \mathrm{g} \mathrm{L}^{-1}$ and $20 \mu \mathrm{g} \mathrm{L}^{-1} \mathrm{P} 4$ decreases with higher OVA concentration, which also suggests an influence of OVA on the binding of free P4 with the antibody in solution (cf. Fig. 5b and d). Obviously, OVA has a binding affinity or (antibody-)shielding propensity towards P4, maybe due to a hydrophobic binding pocket or surface area.

Table 5 Influence of blocking agents on the progesterone-specific LFIA performance

\begin{tabular}{ll}
\hline Blocking agent $^{\mathrm{a}}$ & mAb 49.3/ P4-7 $\alpha$-CET \\
\hline BSA & Used as common blocking agent, complete inhibition $^{\mathrm{b}}$ \\
OVA & Nearly no inhibition $^{\mathrm{b}}$ \\
$\beta$-Lactoglobulin & Nearly no inhibition $^{\mathrm{b}}$ \\
Lactoferrin $_{\text {Casein hydrolysate }}$ & No recognition at the test line \\
PVP $^{\mathrm{c}}$ & Speed reduction due to obstruction, nearly no inhibition \\
$\mathrm{p}^{\mathrm{b}}(\mathrm{MVEMA})^{\mathrm{d}}$ & Less recognition at test line, smear on strip, nearly no inhibition $^{\mathrm{b}}$ \\
$\mathrm{TG}^{\mathrm{e}}$ & Aggregation of label, no recognition at test line
\end{tabular}

${ }^{\mathrm{a}}$ A concentration of $10 \mathrm{~g} \mathrm{~L}^{-1}$ was used unless otherwise mentioned

${ }^{\mathrm{b}}$ Inhibition with a concentration of $20 \mu \mathrm{g} \mathrm{L}^{-1}$ progesterone

${ }^{\mathrm{c}} P V P$ polyvinylpyrrolidone, $30 \mathrm{kDa}$

d $p$ (MVEMA) poly(methyl-vinylether-10-maleic anhydride), concentration $1 \mathrm{~g} \mathrm{~L}^{-1}$

${ }^{\mathrm{e}} T G$ teleostan gelatin, concentration $1 \mathrm{~g} \mathrm{~L}^{-1}$ 
The influence of several commonly used blocking agents was tested in the LFIA format. In Table 5 a summary of the results is given for mAb 49.3. BSA was superior to the other blocking components. The mAb 4P01 behaved in a similar way (not shown). It is remarkable that with $\beta$-lactoglobulin a similar phenomenon is observed as with OVA, i.e. no inhibition by $\mathrm{P} 4$ at $20 \mu \mathrm{g} \mathrm{L}^{-1}$. In this case it is tempting to assume a role comparable to the retinol (vitamin A) binding pocket in $\beta$-lactoglobulin [17].

By using lactoferrin even the blank incubation, without free $\mathrm{P} 4$, does not give a response, which indicates that this protein prevents the binding of the antibody-carbon conjugate to the capture antigen. Having a high isoelectric point (approximately 8.7) the overall charge of this protein in the incubation buffer is positive instead of negative, as is the case for the other blocking agents. Whether this charge difference is the explanation for the absence of a blank signal remains to be elucidated. Other blocking agents like casein hydrolysate, polyvinylpyrrolidone and poly(methylvinylether-10-maleic anhydride) affect the performance of the assay and, hence, are not preferred for blocking purposes.

\section{Conclusions}

A monoclonal antibody to progesterone was obtained with good sensitivity and specificity using progesterone-11 $\alpha$ hemisuccinate-bovine thyroglobulin as immunogen. The sensitivity of progesterone-specific EIAs and LFIAs was increased by applying a high concentration of coating conjugate and a high $\mathrm{mAb}$ dilution as reported before using a progesterone-specific immunoassay with TIRF technology [5]. For the LFIA format an $\mathrm{IC}_{50}$ of $0.6-1.2 \mu \mathrm{g} \mathrm{L} \mathrm{L}^{-1}$ progesterone in buffer (depending on the antibody) could be realized which has not been shown before for this analyte in this assay format. Tests on the performance of the LFIA format by changing the sequence of addition of the sample and reagents, and without or with preincubation of some of the reactants, revealed that addition of all the reagents at once was superior. Fortunately, this order of additions is favourable for a fast performance of this assay.

Addition of OVA as blocking agent was detrimental in both progesterone-specific EIAs and LFIAs. Based on the results with and without free progesterone we suggest that OVA prevents binding of the antibody to the immobilized capture antigen and/or binds to the immobilized capture antigen and the analyte in solution. The presence of a hydrophobic binding pocket on the protein could, however, not be confirmed. Application of several other, commonly used blocking agents gave no better performance than BSA. These results emphasise that only blocking agents that do not interact with the specific antibody and/or antigen should be used.
Often LFIAs allow direct application of bodily fluids such as saliva, blood and urine [1]. Our focus was on bovine milk, but then additional sample pretreatment appeared to be required to assay progesterone with an LFIA format. We found that solid-phase extraction might give sufficient purification [18], but more effort is necessary to implement this idea in an off-laboratory LFIA test. Finally, validation of a progesterone-specific LFIA with other quantitative methods (e.g. GC-MS [19] or LC-MS [20] and a validated EIA [13]) is required before routine use.

Acknowledgements The Dutch Technology Foundation (STW) supported the study; grant number GPG 06038. Special thanks to Dr F. Kohen (Weizmann Institute of Science, Rehovot, Israel) for the generous gift of P4-11 $\alpha$-HS-OVA conjugate and to Dr W.M.M. Schaaper (Pepscan Therapeutics BV, Lelystad, the Netherlands) for help with the preparation of the biotin-P4 conjugates.

Open Access This article is distributed under the terms of the Creative Commons Attribution Noncommercial License which permits any noncommercial use, distribution, and reproduction in any medium, provided the original author(s) and source are credited.

\section{References}

1. Posthuma-Trumpie GA, Korf J, van Amerongen A (2009) Anal Bioanal Chem (in press)

2. Wang S, Zhang C, Zhang Y (2005) Anal Chim Acta 535:219-225

3. Tschmelak J, Proll G, Gauglitz G (2004) Biosens Bioelectron 20:743-752

4. Tschmelak J, Proll G, Gauglitz G (2004) Anal Chim Acta 519:143-146

5. Tschmelak J, Käppel N, Gauglitz G (2005) Anal Bioanal Chem 382:1895-1903

6. Käppel ND, Pröll F, Gauglitz G (2007) Biosens Bioelectron 22:2295-2300

7. Elder PA, Yeo KHJ, Lewis JG, Clifford JK (1987) Clin Chim Acta 162:199-206

8. Loomans EEMG, van Wiltenburg J, Koets M, van Amerongen A (2003) J Agric Food Chem 51:587-593

9. O'Keeffe M, Crabbe P, Salden M, Wichers J, van Peteghem C, Kohen F, Pieraccini G, Moneti G (2003) J Immunol Methods 278:117-126

10. Fazekas de St. Groth S, Scheidegger D (1980) J Immunol Methods 35:1-21

11. de Boever J, Vandekerchkhove D, Kohen F (1989) Anal Chim Acta 227:119-127

12. Beyerman HC, Hirt J, Kranenburg P, Syrier JLM, van Zon A (1974) Recl Trav Chim Pays-Bas 93:256-257

13. van de Wiel DFM, Koops W (1986) Anim Reprod Sci 10:201-213

14. Sauer MJ, Foulkes JA, O’Neill PM (1989) J Steroid Biochem $33: 433-438$

15. Giraudi G, Giovannoli C, Baggiani C, Anfossi L, Tozzi C (2000) Anal Chim Acta 417:95-100

16. Wu Y, Mitchell J, Cook C, Main L (2002) Steroids 67:565-572

17. Muresan S, van der Bent A, de Wolf FA (2001) J Agric Food Chem 49:2609-2618

18. Posthuma-Trumpie GA (2008) PhD thesis, University of Groningen, Groningen, the Netherlands

19. Siekmann L (1979) J Steroid Biochem 11:117-123

20. Tai SSC, Xu B, Welch MJ (2006) Anal Chem 78:6628-6633 